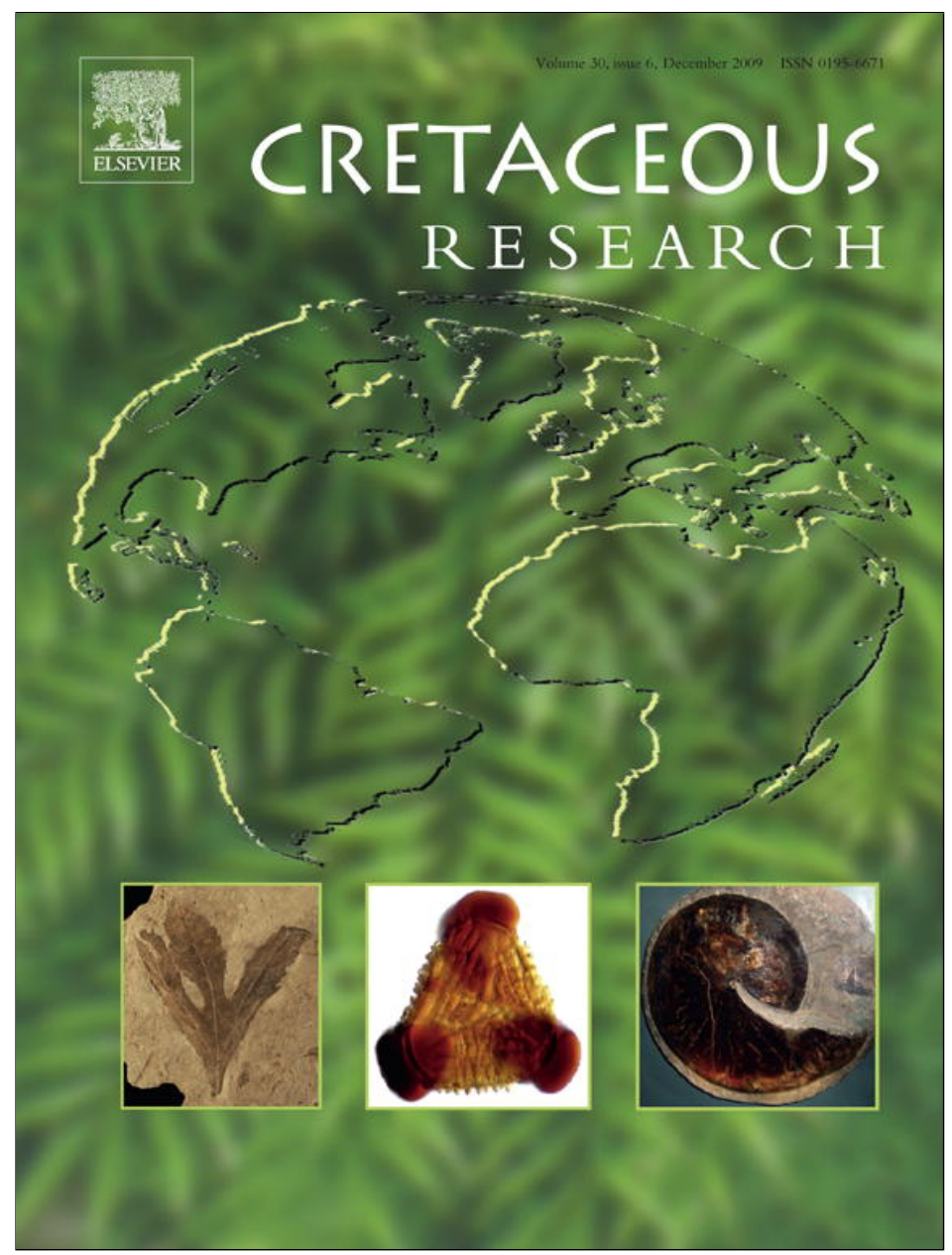

This article appeared in a journal published by Elsevier. The attached copy is furnished to the author for internal non-commercial research and education use, including for instruction at the authors institution and sharing with colleagues.

Other uses, including reproduction and distribution, or selling or licensing copies, or posting to personal, institutional or third party websites are prohibited.

In most cases authors are permitted to post their version of the article (e.g. in Word or Tex form) to their personal website or institutional repository. Authors requiring further information regarding Elsevier's archiving and manuscript policies are encouraged to visit:

http://www.elsevier.com/copyright 


\title{
New dinosaur tracks from Korea, Ornithopodichnus masanensis ichnogen. et ichnosp. nov. (Jindong Formation, Lower Cretaceous): implications for polarities in ornithopod foot morphology
}

\author{
Jeong Yul Kim ${ }^{\mathrm{a}}$, Martin G. Lockley ${ }^{\mathrm{b}}$, Haang Mook Kim ${ }^{\mathrm{c}}$, Jong-Deock Lim ${ }^{\mathrm{d}}$, Kyung Soo Kim ${ }^{\mathrm{e}, *}$ \\ ${ }^{a}$ Department of Earth Science Education, Korea National University of Education, Cheongwon, Chungbuk 363-791, Republic of Korea \\ ${ }^{\mathrm{b}}$ Dinosaur Tracks Museum, CB 172, University of Colorado at Denver, PO Box 173364, Denver, CO 80217-3364, USA \\ ${ }^{\mathrm{c}}$ Department of Geology, Pusan National University, Jangjeon-dong, Geumjeong-gu, Busan 609-390, Republic of Korea \\ ${ }^{\mathrm{d}}$ Natural Heritage Center, National Research Institute of Cultural Heritage, 396-1 Mannyeon-dong, Seo-gu, Daejeon 302-834, Republic of Korea \\ e Department of Science Education, Chinju National University of Education, Shinan-dong, Jinju, Gyeongnam 660-756, Republic of Korea
}

\section{A R T I C L E I N F O}

\section{Article history:}

Received 3 April 2008

Accepted in revised form 6 August 2009

Available online 12 August 2009

\section{Keywords:}

Ornithopod tracks

Ornithopodichnus masanensis

Lower Cretaceous

Jindong Formation

Korea

\begin{abstract}
A B S T R A C T
Twelve trackways of ornithopods from Lower Cretaceous lacustrine margin deposits of the Jindong Formation represent new dinosaur trackways described from Korea. The site, discovered during highway construction, was rescued by removing the most important trackways to the Korean Natural Heritage Center in Daejeon, where they are on permanent display. The new ichnotaxon Ornithopodichnus masanensis ichnogen. et ichnosp. nov. is recognized as a distinctive robust tridactyl track, slightly wider than long $(1 / \mathrm{w}$ ratio $=0.91)$, with positive (inward) rotation. The toe prints are very thick, broad and U-shaped, resulting in a trefoil outline with a smoothly rounded hind margin. Digit III is short and projects anteriorly much less than digit II and IV (= weak mesaxony). Divarication of digits II-IV is about $70^{\circ}$ with interdigital angle II-III larger than III-IV. Trackway width is narrow and the stride length/track length ratio is about 4.2-4.6. The Ornithopodichnus trackways evidently represent gregarious blunt-toed Iguanodon-like bipedal ornithopods, although poorly preserved manus traces are discerned in a few trackways. Ornithopodichnus is distinct from other well known iguanodontid tracks that display much stronger mesaxony and indicates a polarity in ornithopod foot morphology that can be verified by reference to known foot skeletons.
\end{abstract}

(c) 2009 Elsevier Ltd. All rights reserved.

\section{Introduction}

South Korea is of prime important in vertebrate ichnology and it has the largest concentration of Cretaceous dinosaur and bird track sites reported from anywhere on the Asian continent (Lockley et al., 2006). Since dinosaur tracks were first reported from the Jindong Formation of the Cretaceous Gyeongsang Basin (Yang, 1982a), there has been a rapidly growing literature on dinosaur and bird track sites in the Gyeongsang Basin (Yang, 1982b; Lim et al., 1989,1994,1995a,b; Lim, 1990,1995; Lockley et al., 1991,1992,2006,2008; Lee et al., 2000,2001; Paik et al., 2001; Huh et al., 2003, and references therein), the Uhangri area of the Haenam Basin (Huh et al., 1997,2003), the Hwasun area of the Neungju Basin (Huh et al., 2006), and the Yeosu area (Huh et al., 2001).

\footnotetext{
* Corresponding author.

E-mail address: kimks@cue.ac.kr (K.S. Kim).
}

To place the Masan track site in context it is important to mention four track rich areas: Goseong, Haenam, Hwasun, and Yeosu (Fig. 1). In addition to proving material for comparisons between sites and ichnites, they have all recently had their importance emphasized by being designated as Korean (National) Natural Monuments included in a serial nomination to UNESCO as possible World Heritage sites.

In Goseong County 516 dinosaur trackways recorded from the Jindong Formation (in the Sangjok area) represent one of the most famous dinosaur track regions in the world, and a very important component of the East Asian and global track record (Lockley et al., 2006). In the Uhangri area of the Haenam Basin, dinosaur tracks together with new pterosaur and bird tracks were also reported in abundance (Lockley et al., 1997; Hwang et al., 2002; Huh et al., 2003). More than 60 well-preserved theropod trackways were recently reported from the Hwasun area in the Neungju Basin and used to calculate speed estimates (Huh et al., 2006). Recently 82 trackways of (Campanian to Maastrichtian) dinosaurs were 


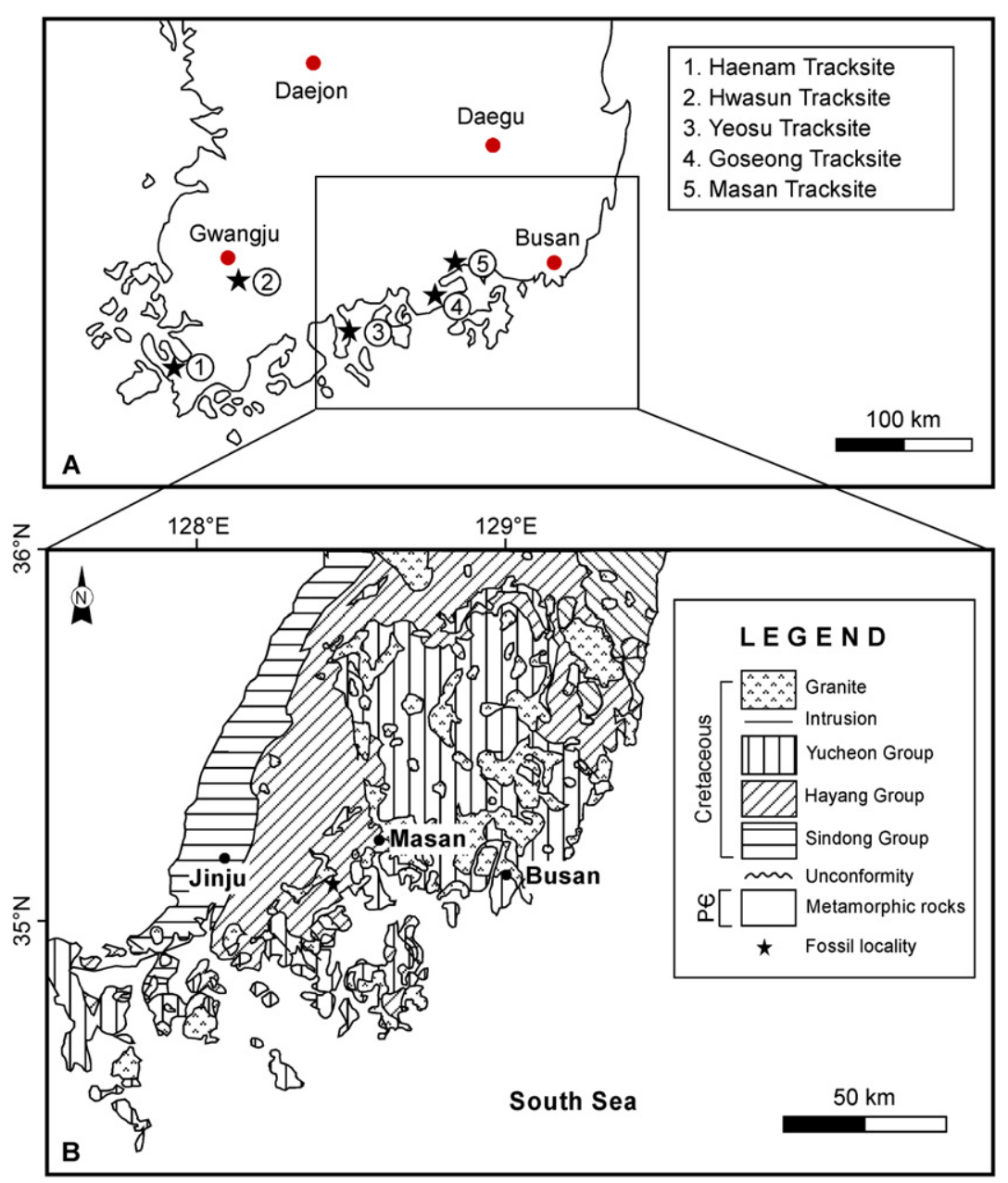

Fig. 1. Well-known dinosaur track rich areas in Korea (A) and geological map showing ornithopod tracks locality (B).

reported from the Yeosu area (Huh et al., 2001) and interpreted as the youngest dinosaur tracksites in Asia.

Dinosaur tracks previously reported from the Cretaceous strata of Korea were reviewed (Lee et al., 2001; Huh et al., 2003) who concluded that the majority of dinosaur tracks were recorded from the Aptian-Albian Hayang Group in the Gyeongsang Basin and from the Cenomanian-Maastrichtian Yucheon Group in the Gyeongsang, Haenam, Neungju basins, and the Yeosu area.

The purpose of this paper is to describe, distinctive wellpreserved ornithopod tracks, herein assigned to Ornithopodichnus masanensis ichnogen. et ichnosp. nov. from the Lower Cretaceous (Albian) Jindong Formation of Masan area, and compare them with the Korean and global track records.

\section{Geological setting}

The Gyeongsang Basin, the largest nonmarine sedimentary basin in Korea, is located in the south-eastern part of the Korean Peninsula. The outlying smaller basins which occur along the Ogcheon Fold Belt in the south-western to central areas are distributed with a NE-SW trend. They are interpreted as extensional basins formed in the overriding continental plate and frontal arc caused by oblique convergence, giving rise to strike-slip movement (Chun and Chough, 1992). This movement was forced along the Ogcheon Fold Belt by the amalgamation of the Chinese and Korean plates that began in Jurassic times (Lee et al., 1999).
The Gyeongsang Supergroup is divided into the Sindong and Hayang groups, mainly comprised of thick siliciclastic sequences of alluvial, fluvial and lacustrine sediments, and the Yucheon Group characterized by the dominance of volcanic rocks (Chang, 1975). Because the ornithopod tracks herein described come from the Jindong Formation in the Hayang Group (Fig. 2) only this unit is described in detail below. The Sindong Group is confined to the western margin of the Gyeongsang Basin with a general NNE-SSW trend (Fig. 1), where deposits in the Nagdong Trough are 2000 to $3000 \mathrm{~m}$ thick. The Sindong Group consists of the Nagdong, Hasandong, and Jinju formations, generally showing a finingupward trend and three facies associations characterized as alluvial fan fringe, fluvial system, and shallow lake (Choi, 1986a,b,c). The Sindong sediment source areas are found to have been to the WNW based on paleocurrent analysis (Chang and Kim, 1968; Kim, 1994; Cheong and Kim, 1996). The occurrence of calcisol and vertisol indicates that climates during the Sindong deposition were arid to semi-arid (Paik and Lee, 1994; Paik and Kim, 1995; Paik and Lee, 1998). Abundant plant fossils collected from the Nagdong Formation were correlated with the floras of the Tetori Group in Japan (Tateiwa, 1925,1929). The Sindong molluscan faunas have been studied extensively and all are assigned to non-marine taxa (Yang, 1974,1975,1976,1978a,b,1979,1982a). In addition, charophytes and non-marine ostracodes were also recovered from the Nagdong and Jinju formations, respectively (Choi, 1987,1989a,1990). Based on molluscan faunas the age of the Sindong Group has been 


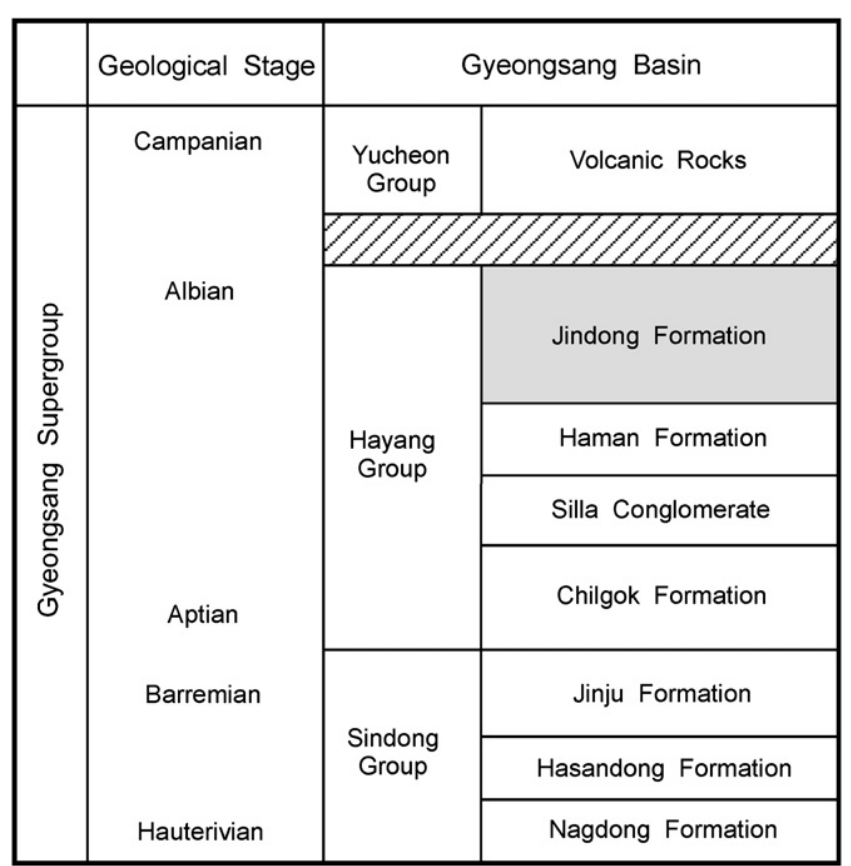

Fig. 2. Stratigraphy of the Gyeongsang Supergroup. Geological ages are based on palynomorphs (Choi, 1985, 1989; Yi et al., 1994) and Lee et al. (2001).

determined as Aptian to Albian (Yang, 1982a) and as Hauterivian to Barremian based on palynomorphs (Choi, 1985,1989; Yi et al., 1994, Fig. 2) and ostracods (Matsukawa et al., 1998).

The Hayang Group is $1000-5000 \mathrm{~m}$ thick. Its upper part contains the track rich Haman and Jindong formations (Fig. 2). Various lines of evidence, including the aforementioned molluscs, ostracods, and palynomorphs suggest that the Hayang Group is Aptian to early Albian in age (Choi, 1985,1989; Yi et al., 1994). The overlying 2000 to $3000 \mathrm{~m}$ thick Yucheon Group, unconformably overlying the Hayang Group, consists of volcanic and associated sedimentary rocks. No fossils are known so far from the Yucheon Group and its isotopic age is $83 \mathrm{Ma}$ by ${ }^{40} \mathrm{~K} /{ }^{40} \mathrm{Ar}$ (Doh and $\mathrm{Kim}$, 1994).

\section{Occurrence of tracks}

The ornithopod tracks originate from a study area (Figs. 3-6) that was a highway construction site, where they occurred on a bedding surface of a $40 \mathrm{~cm}$-thick unit of light gray, fine-grained tuffaceous sandstone which is intercalated within laminated black shale of the Jindong Formation. Strike and dip of the bedding plane are about $\mathrm{N} 20^{\circ} \mathrm{E}$, and $10^{\circ} \mathrm{SE}$ respectively. Well-developed mud cracks, interference ripple marks, rain drop imprints, and plant fragments are frequently observed in the black shale. Rare intercalations of thin tuffaceous sandstone in black shales of the Jindong Formation have been interpreted as being formed in a lacustrine environment (e.g., Choi, 1986c).

The outcrop of the track-bearing bedding surface had a maximum east-west length of 26 meters and is up to 8 meters from north to south (Figs. 3 and 5). The total area of the outcrop of the track-bearing bedding surface was approximately $130 \mathrm{~m}^{2}$. As shown in Fig. 5, a total of 105 discrete ornithopod tracks were mapped, and twelve well-defined trackways consisting of 68 tracks were clearly recognized (Fig. 5). However, the remaining 38 tracks were either isolated or too closely clustered, especially in the southwest of the original outcrop, to recognize individual trackways. Recognition of discrete trackways was also difficult in this area due to small sauropod tracks closely associated with ornithopod tracks on the same surface.

In order to preserve as much of the site as possible a major excavation was undertaken to remove the most important trackways (1-5). These were relocated to the Korean Natural Heritage Center in Daejeon, where they were placed on display in a covered courtyard near the main entrance. Shown in Fig. 5 they are laid out in the form a giant sample cabinet with trackways 1-5 and three unnumbered sections arranged in parallel. As the slabs each weighed several tons it was not possible to cut them into sections that included more than 4 or 5 consecutive tracks. Nevertheless the excavation and relocation was one of the largest operations of its kind to rescue dinosaur tracks. As a result the holotype and paratype trackways (1-5) are identified and can be correlated with the original map (Fig. 5).

The twelve originally-mapped trackways were nearly parallel and represented nearly the same southeastward direction of movement. In addition, trackways composed of relatively small tracks appear beside by those composed of relatively large tracks (trackways 1,2,3, and 5). As outlined below, these observations may suggest that gregarious ornithopods flanked and possibly guided by adults walked southeastward on the lacustrine margin environment.

\section{Systematic description of tracks}

\subsection{General ichnotaxonomic considerations}

Since the first report of so called Iguanodon tracks from the Cretaceous of England in the 1840s, there have been few systematic efforts to review the ichnotaxonomy of large Cretaceous ornithopod tracks. As discussed below, Sarjeant et al. (1998) formalized the description of Iguanodon tracks with the introduction of the ichnogenus Iguanodontipus, and briefly reviewed other names applied to tracks of presumed iguanodontid and/or large ornithopod affinity. Lockley and Wright (2001) viewed the distribution of tracks of quadrupedal ornithopods without detailed analysis of their ichnotaxonomy. In the formal descriptions and discussion that follow we argue that large short, blunt-toed, weekly-mesaxonic large ornithopod tracks have never formally be named, and that they represent distinct morphotypes that have been recognized elsewhere in Korea, and in Europe (Moratalla, 1993) without previously having been named.

We also note that as many ornithopod trackmakers were facultative bipeds, it is possible, as in this case, to describe an ichnotaxon that appears to be predominantly bipedal, even though indistinct manus traces may occur in a few cases. This may be because the trackmaker was overprinting its manus tracks, or because it alternated between bipedal and quadrupedal progression. In either event a distinctive ichnotaxon based on pes morphology could, in theory, be appropriate for the identification of additional material with similar pes morphology but additional manus traces. Thus, ichnologists should not exclude the possibility of future discoveries of other representatives of any given ichnotaxon, (Ornithopodichnus in this case), where manus tracks are more clearly defined and amenable to further study. As noted above, the abundant the material studied herein was rescued from a construction site, and has the potential to be studied further through judicious preparation to remove fill that still adheres to some of the tracks. This might shed further light on features that might be manus traces. However, such work would be specialized, time consuming and require the appropriate permits from the Natural Heritage Center. 

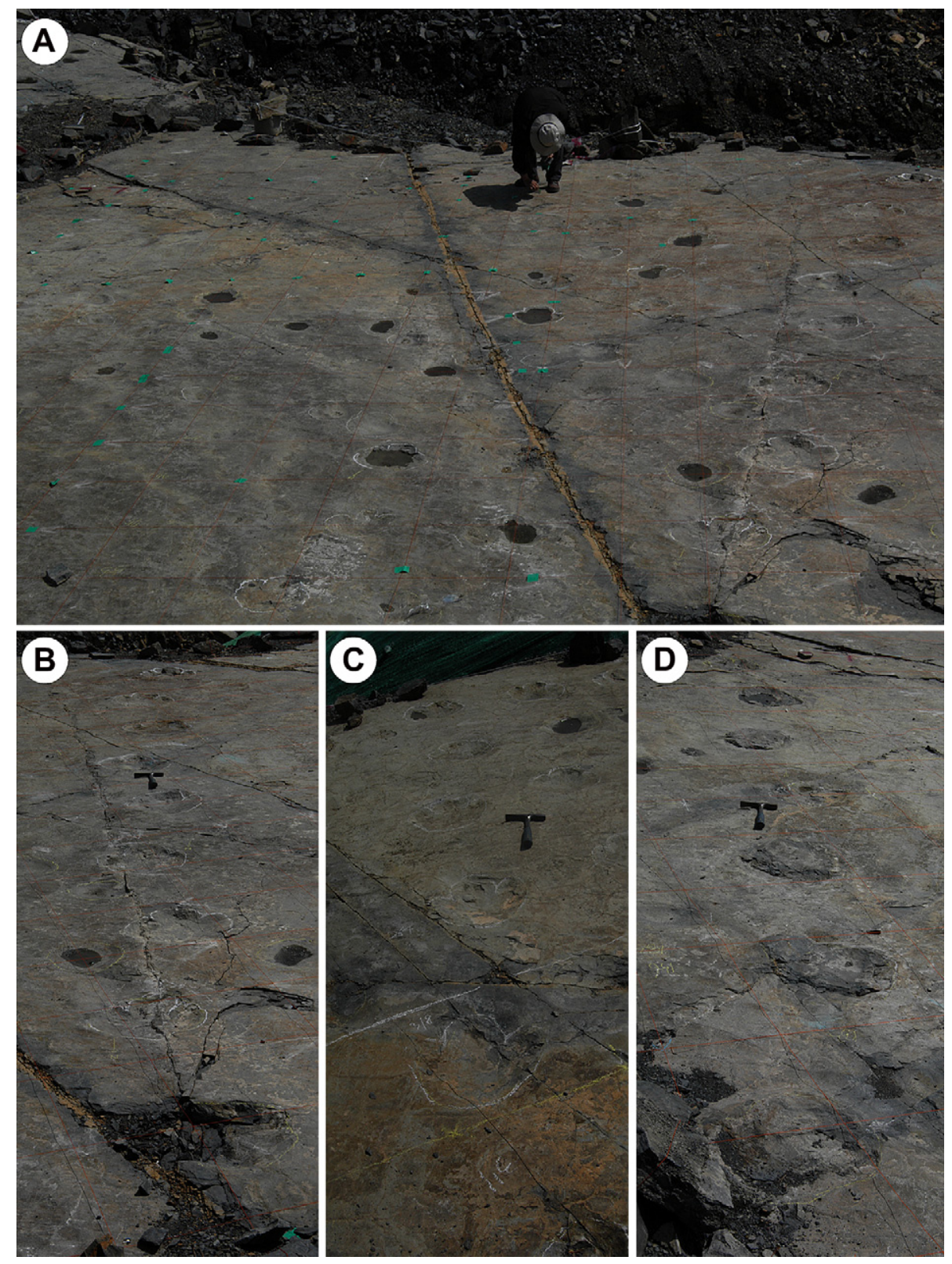

Fig. 3. Outcrop view of study area and track-bearing bedding surface. A, outcrop showing the trackways-bearing bed; B, trackway 2; C, trackway 4; D, trackway 5 .

Thus, before entertaining further 'preparation work, that would change the present track preservation characteristics, and lead to uncertain conservation outcomes, we proceed with the present descriptions noting that the sample is large, comprising multiple clearly defined trackways. Many of have sediment rims that indicate that they are original tracks (not undertracks). Moreover the sample is well curated and accessible to further study by bona fide researchers.

\subsection{Formal descriptions}

\section{Ornithopodichnus ichnogen. nov.}

Type ichnospecies. Ornithopodichnus masanensis

Diagnosis. Narrow trackway of a large facultative biped. Weakly mesaxonic tridactyl pes tracks with very thick, broad U-shaped digit impressions shallowly separated only in the distal part and with smoothly rounded hind margin. Total divarication of digits II-IV about $65-70^{\circ}$, interdigital angle of digits II-III smaller than those digits III-IV. Pes pace angulation about $170^{\circ}$, tracks rotated positively (inwards). Ratios of pes stride to track length about 4.1-4.6. External trackway width narrow up to $69 \mathrm{~cm}$, about 1.6 times track width. Manus traces may be present in some trackways.

Etymology. Ornithopod and ichnus (track)

Type specimens. Holotype-NHC1001 (Trackway 5, represented by A in Figs. 4-6): paratypes-NHC $1002 \sim 1005$ (trackways 1-4, see Figs. 4-6) displayed in a covered exhibit at the Natural Heritage Center (NHC) of the National Research Institute of Cultural Heritage, Daejeon, Korea.

Type locality. Road cut between Daepyeongri and Jisanri villages, Jinbuk-myeon, Masan City, $128^{\circ} 40^{\prime} \mathrm{E}, 35^{\circ} 10^{\prime} \mathrm{N}$. About $40 \mathrm{~km}$ west from Busan City and about $40 \mathrm{~km}$ northeast of the Goseong dinosaur tracksite.

Type horizon. Fine-grained sandstone bed, lower part of the Jindong Formation (Lower Cretaceous, Hayang Group).

Remarks. Ornithopodichnus is characteristically a narrow trackway of large facultative biped, revealing tridactyl tracks with very thick, U-shaped toe impressions separated only in the distal 

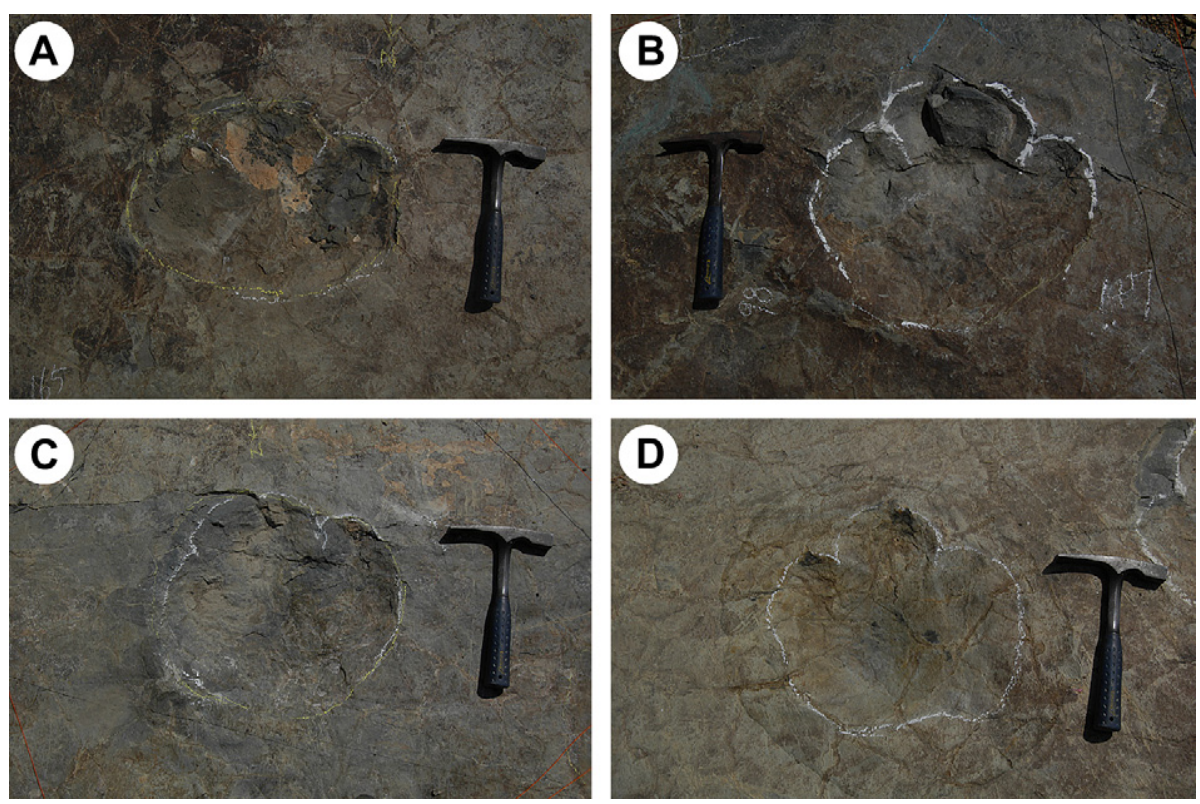

Fig. 4. Examples of individual tracks. A, R2 of trackway 2; B, R4 of trackway 2; C, L3 of trackway 4'; D, L2 of trackway 5.

part and with a rounded hind margin. It also shows positive (inward) rotation, larger width than length, and interdigital angle II-III > III-IV.

\section{Ornithopodichnus masanensis ichnosp. nov.}

Figs. 3 and 4

Diagnosis. As for ichnogenus

Etymology. After Masan City

Type specimens. As for ichnogenus

Type locality. As for ichnogenus

Type horizon. As for ichnogenus

Description. Narrow trackway of large facultative bipedal ornithopod. Pes tracks, about $37-44 \mathrm{~cm}$ in length, and about $41-48 \mathrm{~cm}$ width in trackways 4 and 2 respectively (Table 1 ). Track width $(\mathrm{w})$ greater than length (l) giving $\mathrm{l} / \mathrm{w}$ : ratio between 0.90 and 0.92 for trackways 4 and 2 respectively. Mesaxonic tridactyl tracks with very thick, broad U-shaped digit impressions shallowly separated only in the distal part. Smoothly rounded hind margin with a slightly protruding heel pad impression (trackway 2). Total divarication of digits II-IV about $65-70^{\circ}$, interdigital angle of digits II-III slightly smaller than those of digits III-IV (trackway 2), thus slightly asymmetrical arrangement of digits. Pace angulation ranges from $164-175^{\circ}$. Tracks rotated positively (inwards) in pigeon-toed fashion. Stride length/track length ratio averages about 4.3. Stride length variable, gradually increases from $153 \mathrm{~cm}$ to
$166 \mathrm{~cm}$ in trackway 4, varies from 203 to $183 \mathrm{~cm}$ in trackway 2 . Trackway width is narrow, ranges $46-57 \mathrm{~cm}$ (trackway 4) and 64-69 cm (trackway 2), about 1.2-1.3 times track width. Measured data of pes trackway $4^{\prime}$ are incomplete though they resemble those of trackway 4. Manus traces occur sporadically, but their morphology is variable and unclear in the type sample.

Trackway 3 is composed of five tracks, about $44 \mathrm{~cm}$ in length $36 \mathrm{~cm}$ in width (Table 1). Track width is less than track length. Track length/track width ratio is about 1.28. Total divarication of digits II-III is about $50^{\circ}$, which is nearly same or slightly less than that of digits III-IV. Pace angulation ranges from $164-166^{\circ}$. Tracks rotated positively, stride length/track length ratio is about 4.1. External trackway width ranges 48 to $59 \mathrm{~cm}$. Some tracks of trackways 1 and 5 do not clearly show digit separations probably due to preservation.

\section{Comparative ichnology of Ornithopodichnus}

\subsection{Comparisons with Iguanodontipus and so called 'Iguanodon} tracks'

Ornithopodichnus is clearly distinguished in footprint morphology from most tracks attributed to ornithopods, hadrosaurs, and other dinosaurs and so can be classified as a new ichnogenus. As noted above, Sarjeant et al. (1998) reviewed the history and taxonomy of footprints of Iguanodon and erected Iguanodontipus burreyi for the

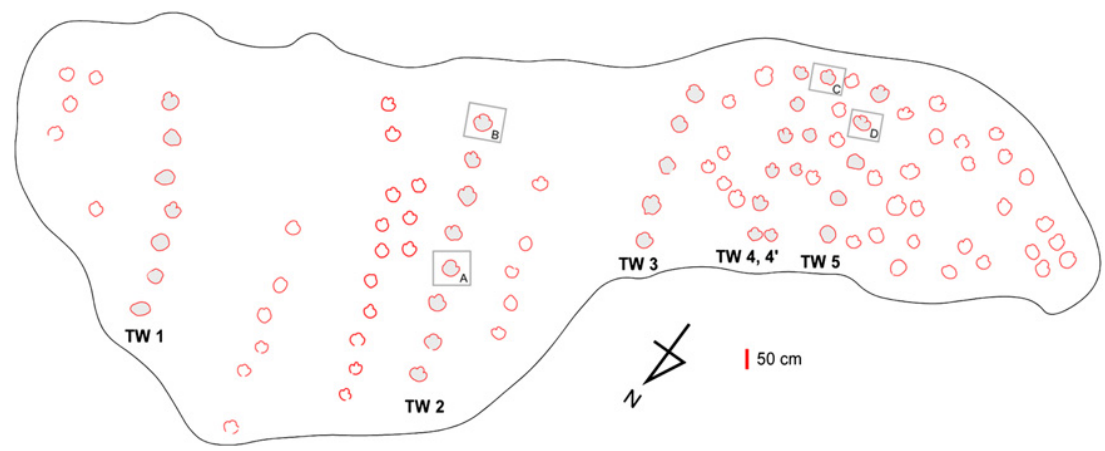

Fig. 5. Map of distribution of ornithopod tracks and trackways in the outcrop of the original study area. A-D in trackways $2,4^{\prime}$, and 5 correspond to individual tracks shown in Fig. 4 . 


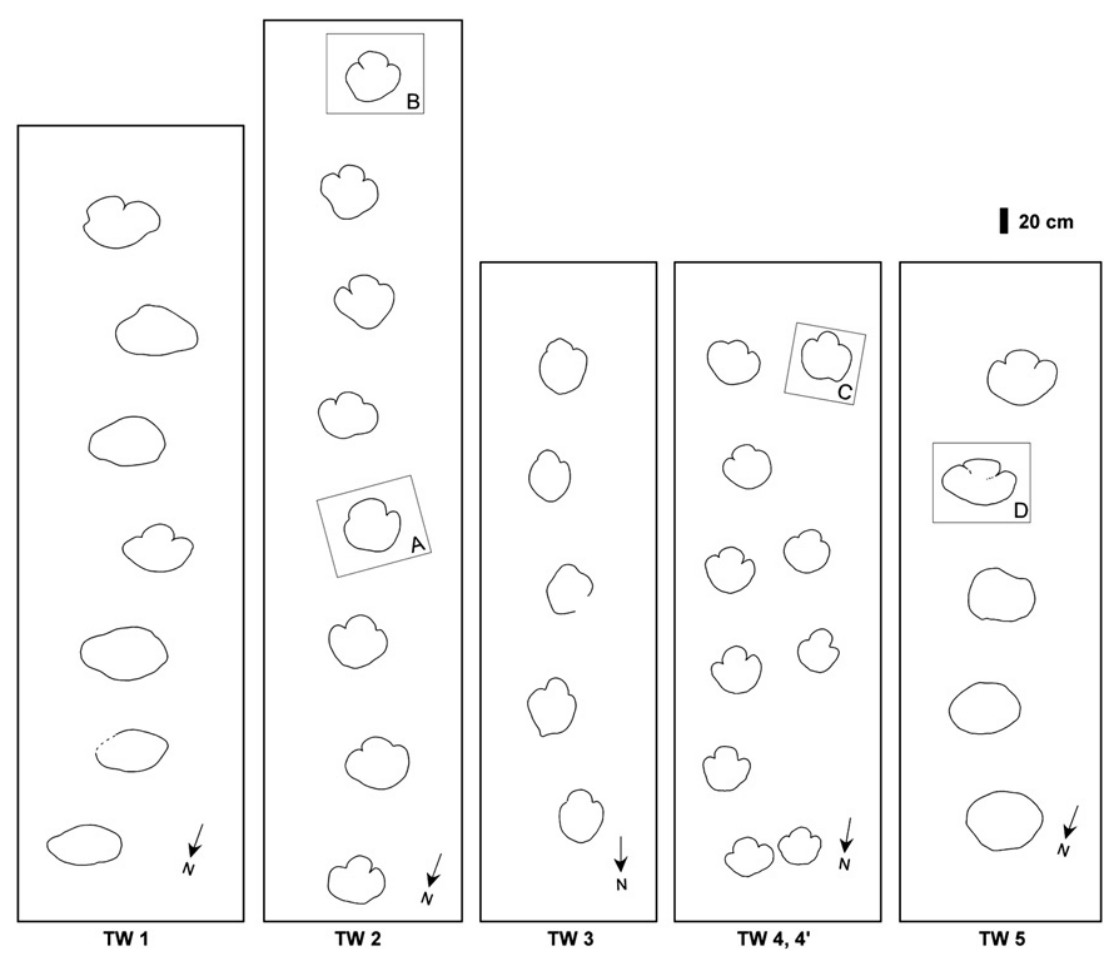

Fig. 6. Line drawings of ornithopod trackways. A-D in trackways $2,4^{\prime}$, and 5 correspond to individual tracks shown in Fig. 4 . These trackway segments are reposited at the Natural Heritage Center, Daejeon.

Table 1

Measurement of Ornithopodichnus trackways

\begin{tabular}{|c|c|c|c|c|c|c|}
\hline $\begin{array}{l}\text { Trackway } \\
\text { No. }\end{array}$ & Track No & $\begin{array}{l}\text { Length } \\
(\mathrm{cm})\end{array}$ & $\begin{array}{l}\text { Width } \\
(\mathrm{cm})\end{array}$ & $\begin{array}{l}\text { Pace } \\
(\mathrm{cm})\end{array}$ & $\begin{array}{l}\text { Stride } \\
(\mathrm{cm})\end{array}$ & $\begin{array}{l}\text { Pace } \\
\text { angle }\left(^{\circ}\right)\end{array}$ \\
\hline \multirow[t]{4}{*}{ TW $4^{\prime}$} & R1 & 34 & 34 & & & \\
\hline & $\mathrm{R} 2$ & 36 & 32 & 70 & 160 & \\
\hline & L2 & 36 & 36 & & 161 & \\
\hline & L3 & 37 & 40 & & & \\
\hline \multirow[t]{6}{*}{ TW 4} & R1 & 34 & 39 & 75 & & \\
\hline & L1 & 36 & 38 & 82 & 153 & 164 \\
\hline & $\mathrm{R} 2$ & 38 & 40 & 80 & 159 & 173 \\
\hline & L2 & 37 & 41 & 82 & 161 & 173 \\
\hline & R3 & 36 & 38 & 84 & 166 & 175 \\
\hline & L3 & 37 & 42 & & & \\
\hline \multirow[t]{8}{*}{ TW 2} & L1 & 40 & 46 & 97 & & \\
\hline & R1 & 44 & 52 & 100 & 203 & 170 \\
\hline & L2 & 44 & 48 & 94 & 197 & 174 \\
\hline & R2 & 44 & 47 & 92 & 183 & 170 \\
\hline & L3 & 40 & 49 & 97 & 183 & 168 \\
\hline & R3 & 44 & 49 & 92 & 187 & 170 \\
\hline & L4 & 44 & 47 & 96 & 186 & 167 \\
\hline & R4 & 42 & 44 & & & \\
\hline \multirow[t]{5}{*}{ TW 3} & $\mathrm{R} 1$ & 44 & 35 & 93 & & \\
\hline & L1 & 45 & 38 & 91 & 182 & 164 \\
\hline & $\mathrm{R} 2$ & 41 & 36 & 91 & 183 & 166 \\
\hline & L2 & 41 & 35 & 91 & 180 & 165 \\
\hline & R3 & 45 & 38 & & & \\
\hline \multirow[t]{5}{*}{ TW 5} & R1 & 48 & 60 & 88 & & \\
\hline & L1 & 40 & 58 & 92 & 177 & 160 \\
\hline & $\mathrm{R} 2$ & 42 & 51 & 92 & 179 & 158 \\
\hline & L2 & 37 & 58 & 92 & 177 & 165 \\
\hline & R3 & 44 & 55 & & & \\
\hline \multirow[t]{7}{*}{ TW 1} & L1 & 30 & 54 & 77 & & \\
\hline & R1 & (32) & (54) & 77 & 151 & 155 \\
\hline & L2 & 39 & 63 & 78 & 153 & 160 \\
\hline & $\mathrm{R} 2$ & 36 & 51 & 82 & 153 & 150 \\
\hline & L3 & 36 & 55 & 83 & 162 & 155 \\
\hline & R3 & 38 & 60 & 85 & 165 & 147 \\
\hline & L4 & 40 & 55 & & & \\
\hline
\end{tabular}

tridactyl pedal imprints of dinosaurs with three robust or fleshy digits and a smoothly curved or very slightly flattened heel found in an assemblage from the Isle of Wight (Hampshire, England). Such tracks had previously been referred to simply as 'Iguanodon tracks' in contravention of ICZN guidelines. Various un-named tracks from the Wealden of East Sussex, England described by Parkes (1993) are similar in size to the Masan tracks, but they show deeply-separated digits and pronounced heel impressions which distinguish them from those of Ornithopodichnus.

Ornithopodichnus differs fundamentally from Iguanodontipus in having thicker, broader, U-shaped digits with little anterior separation, weak mesaxony and a smoothly-rounded hind margin. Ornithopodichnus is also distinguished from Iguanodontipus in the reduced track length/width ratio. Although the size of tracks, interdigital angle between digits II-IV, pace angulation, and trackway width may be similar, the inherent shape difference is consistent throughout trackways and assemblages: this implies that the distinct morphology is independent of size and therefore of morphological significance and not an artifact of preservation.

\subsection{Comparisons with Caririchnium and other large ornithopod tracks from Asia}

Caririchnium isp., reported from the Lower Cretaceous of Japan (Matsukawa et al., 2005), and numerous ornithopod tracks similar to Caririchnium isp. from the Cretaceous strata of Korea (Huh et al., 2003,2006; Lockley et al., 2006) are distinctly different from Ornithopodichnus in general outline: the former has three blunt, clearly separated digits and heel pad impressions that are either oval or subtriangular, and sometimes bilobed. In addition Caririchnium often has associated manus tracks. Likewise, unnamed tracks from the Lower Cretaceous of Hebei Province, China have clearly separated digit impressions and represent quadrupeds (You and Azuma, 1995; Lockley and Matsukawa, 1998). An iguanodontid track from 
the Lower Cretaceous of Tongfosi, Yenji Province of northeast China (Matsukawa et al., 1995, fig. 6c) differs from Ornithopodichnus in digital degree of separation of the digit traces and size of track. The Yenji track is also an isolated natural cast that is difficult to compare with the large Masan sample.

Tracks similar to Ornithopodichnus have recently been recognized from the Hwasun site (Huh et al., 2006) but they have not been named. They are presently under study (Lockley et al., in review).

\subsection{Comparisons with large ornithopod tracks from North America}

In addition to Caririchnium from Asia, the ichnogenus is also represented by the ichnospecies Caririchnium leonardii from North America (Lockley, 1987; Lockley and Wright, 2001), which is more elongate, with sharper digit terminations, and more strongly mesaxonic than Ornithopodichnus. The ichnospecies Amblydactylus gethingi from Canada (Currie and Sarjeant, 1979) is a slightly elongate track with relatively sharp terminations to the digit traces. It is also represented by a trackway indicating quadrupedal progression. Amblydactylus kortmeyeri is more transverse, but again has relatively sharp terminations to the digit traces and evidence of quadrupedal progression. Ornithopodichnus is distinguished from the clover-leaf-shaped unnamed tracks from the Upper Jurassic or Lower Cretaceous of Mexico especially in digit separation and pad impressions (Ferrusquia-Villafranca et al., 1978).

\subsection{Comparisons with large ornithopod tracks from Spain}

Ornithopodichnus differs from the iguanodontid dinosaur tracks from the Lower Cretaceous of Regumiel de la Sierra, province of Burgos, Spain (Moratalla et al., 1994, fig. 4), which have more acute digital toe trace terminations and also more pronounced heel margin than the former. However, we note that descriptions of large iguanodontid tracks from the province of Burgos, Spain in the $\mathrm{PhD}$ thesis of Moratalla (1993) refer to tracks with short blunt digits and smoothly rounded heel much like Ornithopodichnus. The tracks are also wider than long (mean width and length values are 64.3 and $53 \mathrm{~cm}$ respectively: $1 / \mathrm{w}=0.82$ ). However, the trackway parameters are different: the step is short with a high pace angulation $\left(105^{\circ}\right)$. Because the description and the name - 'Brachyguanodonipus prejanensis' - were proposed in a PhD thesis (in Spanish) the name has no formal status in ichnotaxonomy. Given that the Spanish form is larger and more transverse than the Korean form, and also displays different trackway parameters, we consider the two forms distinct. Nevertheless, there are overall similarities in track shape and the Lower Cretaceous age of the two tracks is similar, probably between Valanginian and Aptian in both cases.

\section{Interpretation of the trackway assemblage}

\subsection{Track and trackway distributions}

A total of 105 tracks are assigned to Ornithopodichnus masanensis (Fig. 5) are recognized in association with unnamed sauropod tracks in an area of approximately $15 \times 5 \mathrm{~m}$ on the outcrop surface (Figs. 4 and 5). This represents an example of one of the highest densities of dinosaur tracks in the Cretaceous strata of Korea.

As shown in Fig. 5, all the Ornithopodichnus trackways are parallel to each other oriented in one preferred southward direction. They also show consistent intertrackway spacing (sensu Lockley, 1989) across much of the site. Parallel ornithopod trackways are relatively common at Cretaceous sites in Asia (Lockley et al., 2006; Zhang et al., 2006) and in North America (Lockley and
Hunt, 1995; Matsukawa et al., 1999) and are typically considered to indicate gregarious behavior. Iguanodon was the most-likely producer of the tracks, though no skeletal remains are found in the Masan locality. This is the typical of track-rich, bone-poor sites in the Cretaceous of Korea (Huh et al., 2003, 2006; Lockley et al., 2006).

\subsection{Trackmaker size and speed estimates}

Dinosaur tracks have often been used for estimating size and speed of track-makers (Thulborn, 1990 and references therein). Table 2 shows the estimated height at the hip and speed of Ornithopodichnus producers. As shown in Table 2, heights at the hip are estimated as $211 \mathrm{~cm}, 205 \mathrm{~cm}, 251 \mathrm{~cm}, 251 \mathrm{~cm}, 239 \mathrm{~cm}$ and $217 \mathrm{~cm}$ in the trackways $4,4^{\prime}, 2,3,5$, and 1 respectively. On the basis of correlation between height at the hip and body mass (Thulborn, 1990), the body mass of the Ornithopodichnus producers may be estimated at about one to five tons.

Relatively stride length (stride length/height at the hip, or SL/h), has been used to define three dinosaur gaits as walking $(<2)$, trotting $(2-2.9)$, and running $(2.9<)$ (Thulborn, 1990). According to these definitions, all speed estimates derived from Ornithopodichnus trackways suggest track-makers that were walking. Thulborn $(1990)$ provided an equation, $\mathrm{V} \approx(1.42 \mathrm{~h})^{0.5}$ for predicting the average walking speed of bipedal dinosaur. By using this equation speeds of the Ornithopodichnus-makers are estimated as 1.71 to $1.89 \mathrm{~km} / \mathrm{h}$. Gradually increasing stride length and pace angle from track R1 to track L3 in trackway 4 (Fig. 3, Table 1) suggest an individual gradually increasing its speed. These data indicate that the Ornithopodichnus-makers, probably ornithopods resembling Iguanodon, were walking slowly in the lake margin environment.

\subsection{Trackmaker affinity}

Tridactyl tracks can be difficult to differentiate because measurable parameters show a continuous range of variation. Although there is broad agreement on the difference between large Cretaceous ornithopod tracks, which are generally as wide, or wider than long, with short steps and inward rotation of the pes, and theropod tracks which are generally elongate with long steps and less rotation, there can be some degree of convergence. In any given sample there are likely to be one or more track types that tend towards elongate (narrow) and wide (transverse forms): i.e., short, wide v. long, narrow polarities not only occur between groups, but recur within groups such as the ornithopods and theropods (Lockley, 2007,2008). Such variation is compounded, and potentially obscured when we consider multiple samples from different stratigraphic levels and regions. Such length/width shape variation is usually correlated with the degree of mesaxony: i.e., the anterior projection of the central toe (digit III) traces relative to those of digits II and IV (Weems, 1992). As inferred by Lockley $(2007,2008)$ such morphological variation is likely part of an

Table 2

Estimated data of height at the hip and speed of Ornithopodichnus producers

\begin{tabular}{llllll}
\hline Trackway No. & $\mathrm{L}(\mathrm{cm})$ & $\mathrm{SL}(\mathrm{cm})$ & $\mathrm{h}^{*}(\mathrm{~cm})$ & $\mathrm{SL} / \mathrm{h}$ & $\mathrm{V}^{* *}(\mathrm{~km} / \mathrm{h})$ \\
\hline TW 1 & 38 & 155 & 217 & 3.08 & 1.76 \\
TW 2 & 44 & 190 & 251 & 3.56 & 1.89 \\
TW 3 & 44 & 182 & 251 & 3.56 & 1.89 \\
TW 4 & 37 & 160 & 211 & 3.00 & 1.73 \\
TW 4 & 36 & 160 & 205 & 2.91 & 1.71 \\
TW 5 & 42 & 177 & 239 & 3.40 & 1.84 \\
\hline
\end{tabular}

L: track length, SL: stride length, SL/h: relative stride length (Thulborn, 1990). ${ }^{*} \mathrm{~h}=5.7 \mathrm{~L}$ (height at the hip of large bipedal dinosaur in general; Thulborn, 1990). ${ }^{* *} \mathrm{~V}=(1.42 \mathrm{~h})^{0.5}$ (average walking speed of bipedal dinosaurs; Thulborn, 1990). 
inherent morphodynamic 'growth program' that is both independent of size and possibly largely independent of mechanically or locomotor-induced digit divarication.

Support for these inferences can be seen in the variation in ornithopod foot skeletons. For example, in the genus Iguanodon (sensu Norman, 1980) there is a strong morphodynamic polarity between the gracile form (I. atherfieldensis) with a relatively long digit III (strong mesaxony) and the robust form (I. bernissartensis) with short digit III (weak mesaxony): see Fig. 7. This could be due to sexual dimorphism (Van Beneden, 1878), but, controversially, according to Paul (2006) the former species should be assigned to the new genus Mantellisaurus. The tracks are also the right age to be of iguanodontid affinity as they predate any known hadrosaur. In this regard it is worth noting that purported hadrosaur tracks from the Lower Cretaceous of Canada (Currie and Sarjeant, 1979; Thulborn, 1990) are likely to be of iguanodontid affinity based on the Aptian age of the deposits. Nevertheless, the same morphological polarity occurs in hadrosaurs. For example, the hadrosaurs Bactrosaurus johnsoni and Gilmoreosaurus mongoliensis from the Iren Dabasu Formation (Gilmore, 1933) have wide and narrow toes respectively with corresponding weak and strong mesaxony. Likewise, the large taxon Zhuchengosaurus (Zhao et al., 2007) has a very short digit III relative to digits II and IV (Fig. 8), whereas there are many large hadrosaur tracks, such as Hadrosauropodus langstoni (Lockley et al., 2004) which provide evidence of a more prominent digit III: i.e., much stronger mesaxony.

Most small basal ornithopods from the Jurassic, including the probable maker of Anomoepus tracks are, in comparison with large, robust Cretaceous forms, very gracile with a relatively long digit III (Thulborn, 1990). Thus, it appears that the smaller, primitive forms tend to be gracile with pronounced mesaxony, whereas large, derived forms with weak mesaxony are more typical of many large Cretaceous ornithopods (Lockley, 2008). The important conclusion is that within various clades of track-making ornithopods, it is possible to recognize variable foot macromorphology expressed in gracile-robust polarities, and variable degrees of mesaxony. Moreover, these reflect real morphological and taxonomic differences between the trackmakers.

\subsection{A possible anomaly or a dimorph}

Trackway 3 has a comparatively high $\mathrm{l} / \mathrm{w}$ ratio (1.28) compared with other Ornithopodichnus trackways (0.91 to 0.92). Because of the contextual evidence of multiple parallel trackways, we rule out inferring a different species of track maker to interpret this difference. Other possible explanations include sexual dimorphism (Dodson, 1976; Irby, 1995; Tresise, 1996), or local variation in substrate conditions. Other possibilities include apparent elongation of the footprints by sliding during faster progression. Trackway 3 represents the smallest trackmaker in the measured group but it has the second longest step and stride (Table 1 ). There is also the possibility that the smaller track makers had more elongate feet. As suggested above, such allometric trends have been noted among tridactyl trackmakers (Weems, 1992), Lockley (2007,2008), and references therein.

\subsection{Associated track types and inferred paleoecology}

Together with these Ornithopodicnhus trackways, many smallsized (about $20 \mathrm{~cm}$ in length and width) sauropod tracks occur on the same bedding surface. Unfortunately, their distribution is too random to clearly recognize the orientation of individual trackways. Moreover, it was not possible to rescue much of this portion of the site. Co-occurrences of large ornithopods and small sauropod tracks, in abundance, on the same bedding surface are quite interesting, because it is not commonly observed. It has been suggested that large ornithopods are found mostly at higher latitudes in more humid climates whereas sauropods are found mainly at low latitudes in drier and warmer climates (Lockley et al., 1994). It has also been noted that, in other Lower Cretaceous track-bearing successions, notably the Jindong Formation, sauropod and ornithopod tracks are mostly mutually exclusive, occurring on different bedding planes in most cases, perhaps suggesting separate movement or migration patterns for these two different herbivore groups. However, there are also some examples of Lower Cretaceous co-occurrences of sauropod and ornithopod tracks at the same horizon, as for example at the Gansu site in China (Zhang
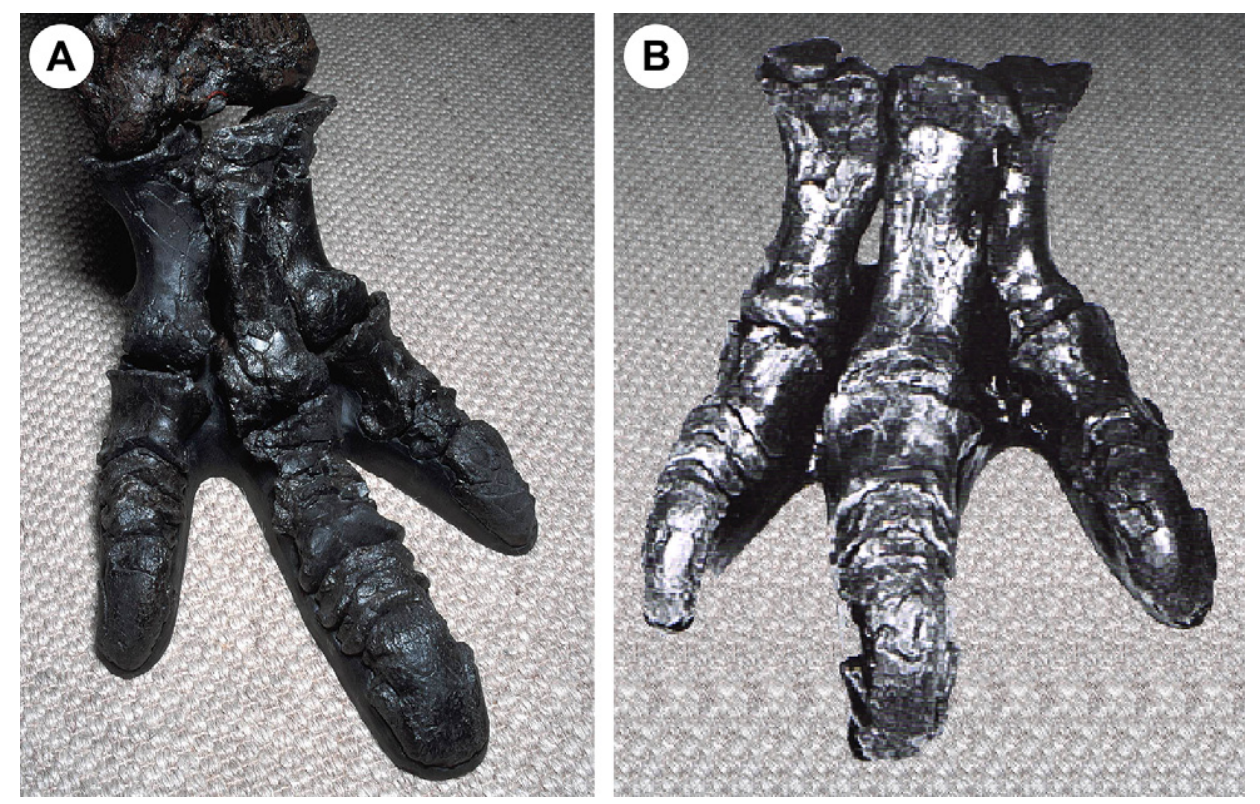

Fig. 7. Photos of the feet of Iguanodon atherfieldensis (A) and Iguanodon bernissartensis (B) showing polarity between robust, weakly-mesaxonic and gracile, strongly-mesaxonic morphologies respectively. Photos courtesy of Pascal Godefroit and Casier (1978). 


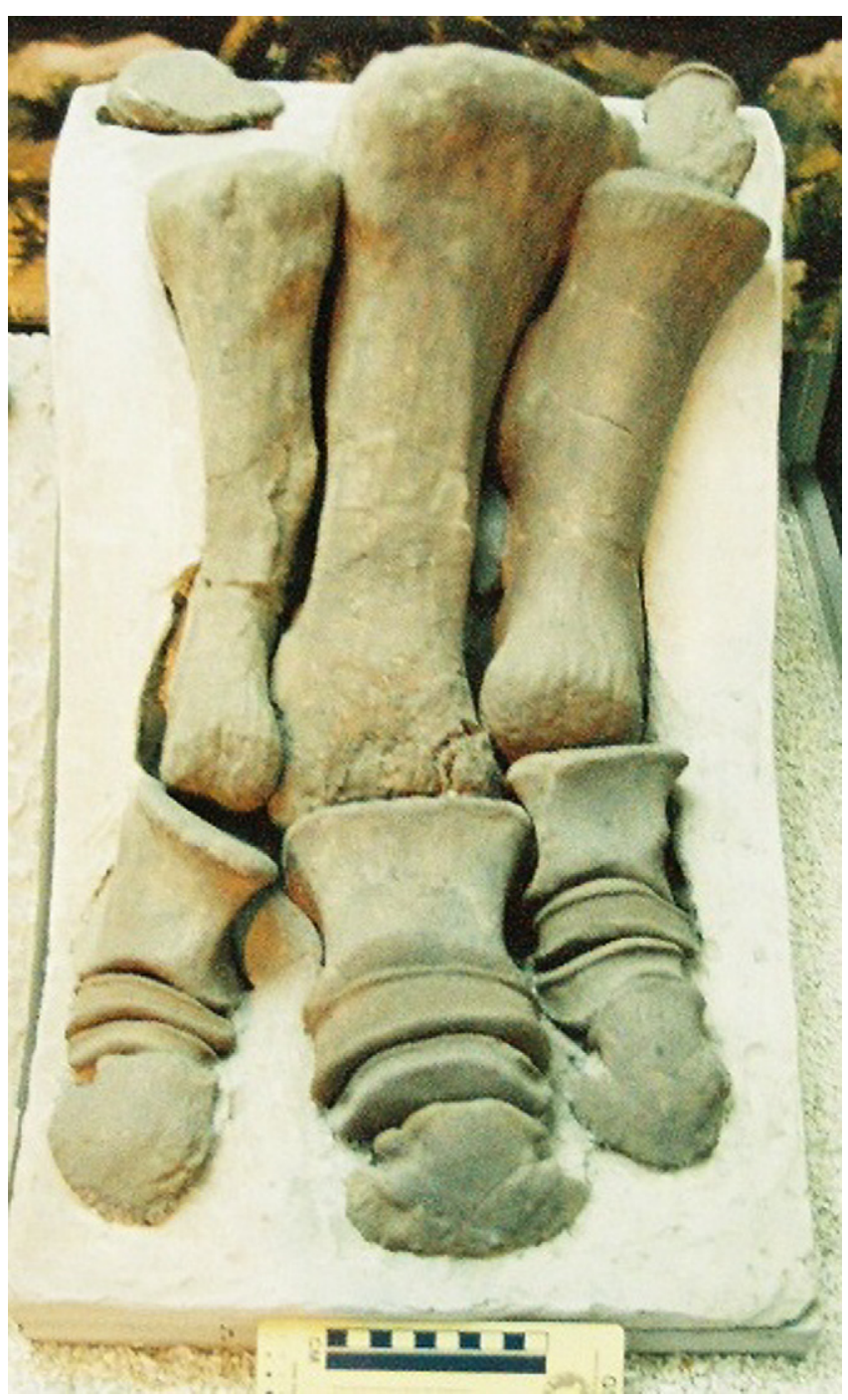

Fig. 8. Photo of a Cretaceous hadrosaur foot skeleton (Zhuchengosaurus) on display at the Institute of Vertebrate Paleontology and Paleonathropology, Beijing (with permission). Note the bluntness of digits II-IV and the limited projection of central digit III beyond digits II and IV. Compare with Zhao et al. (2007, P1 III, fig. 9).

et al., 2006). Such co-occurrences do not prove that the two track types were made at exactly the same time. In laminated and thinly bedded sediments subtle underprints may appear as true tracks, and be difficult to distinguish even with careful study. This cooccurrence suggests that the Masan tracksite might be a part of an Early Cretaceous crossroads of the Jindong lake system (Lockley et al., 1994) which was situated at a similar intermediate paleolatitude between lower-latitude, sub-tropical, sauropod dominated terrain and higher-latitude, temperate ornithopod habitats. Recently Matsukawa and Lockley (2007) speculated on a clockwise movement of gregarious ornithopods along a possible migration route during the Cretaceous in East Asia. The mostly southward direction of all of Ornithopodichnus in this study area may support the speculations of Matsukawa and Lockley (2007), though it is not clear whether this was caused by local paleogeography such as a small lake shoreline or not. The Masan track site is too small and isolated from most tracksites to form part of a larger regional picture at a well defined stratigraphic level as is the case with the Dinosaur Freeway (Cretaceous Dakota Group) in Colorado (Lockley et al., 1992).

\section{Conclusions}

Ornithopodichnus masanensis ichnogen. et ichnsp. nov. represents a hitherto unnamed wide, blunt-toed iguanodontid track type with weak mesaxony. Such track types have been recognized elsewhere in Asia and Europe, but have not been formally named or discussed in detail. Our inferences regarding polarities in size, width, and mesaxony in ornithopod footprints are supported by independent evidence of polarity or 'dimorphism' in the skeletal remains of Cretaceous ornithopods. Consequently such inferences are valuable for ichnology because they suggest that inherent variation in the ornithopodan 'growth program' produces recognizable, size-independent differences in track morphology that allow the differentiation of ichnotaxa, even if the track-making genus can not be identified. We conclude that Ornithopodichnus, and the 'informally-named' Spanish ichnite (Brachyguanodonipus) were likely made by blunt-toed iguanodontids, but not necessarily by the genus Iguanodon, although I. bernissartensis or a closely related species is a likely candidate. In this regard we note that the ornithopod tracks illustrated by Matsukawa and Lockley (2007, fig. 3) from the Lower Cretaceous of Shandong Province, also show a very short digit III trace, as well as manus traces. Similar tracks at the Hwasun quarry in Korea (Huh et al., 2006), are under investigation (Lockley et al., in review) and appear similar to Ornithopodichnus. Thus, we conclude that this blunt toed Ornithopodichnus morphotype is relatively common in the Cretaceous of East Asia, but also occurs in Europe. We, also predict that the polarity between strongly and weakly mesaxonic ornithopods may be recognized in other Cretaceous ichnofaunas from different regions.

\section{Acknowledgements}

This research was carried out as a part of 2007 Research Project "Study on Preservation and Conservation Scheme of 3D Record of Dinosaur Tracksites" supported by the Natural Heritage Center of National Research Institute of Cultural Heritage. Authors thank Dr. S.Y. Yang for useful comments in the field. M.G.L. also thanks Rihui Li, Qingdao Institute of Marine Geology, for support of travel and field work in Shandong Province. We also thank Pascal Godefroit (Institute Royal des Sciences Naturelles de Belgique) for providing the photos used in Fig. 7. We also thank both reviewers for their helpful comments and suggestions. Authors thank S. H. Kim, S. J. Lee, J. O. Woo, H. J. Park and H. S. Kim, who helped in the field and laboratory.

\section{References}

Casier, E., 1978. Les Iguanodons de Bernissart, second ed. Institut Royal des Sciences Naturelles de Belgique, Brussels, 166 pp.

Chang, K.H., 1975. Cretaceous stratigraphy of southeast Korea. Journal of the Geological Society of Korea 11, 1-23.

Chang, K.H., Kim, H.M., 1968. Cretaceous paleocurrents and sedimentation in northwestern part of Gyeongsang Basin, Southern Korea. Journal of the Geological Society of Korea 4, 77-97.

Cheong, D.K., Kim, Y.I., 1996. Sedimentological study of the Nakdong Formation to analyse the forming and evolving tectonics of the Cretaceous Gyeongsang Basin, I. Depositional setting, source, and paleocurrent analyses of the Nakdong Formation in the Southwestern Gyeongsang Basin. Economic Environmental Geology 29, 639-660.

Choi, D.K., 1985. Spores and pollen from the Gyeongsang Supergroup, southeastern Korea and their chronologic and paleoecologic implications. Journal of the Paleontological Society of Korea 1, 33-50.

Choi, D.K., 1989. Palynology of the Geoncheonri Formation (Lower Cretaceous), Geoncheon-Ahwa area, Korea. Journal of the Paleontological Society of Korea 5, $1-27$.

Choi, H.I., 1986a. Sedimentation and Evolution of the Cretaceous Gyeongsang Basin, Southeastern Korea, 143. Journal of the Geological Society, London, pp. 29-40.

Choi, H.I., 1986b. Sandstone petrology of the Sindong Group, southwestern part of the Gyeongsang Basin. Journal of the Geological Society of Korea 22, 212-223.

Choi, H.I., 1986c. Fluvial plain/lacustrine facies transition in the Cretaceous Sindong Group, south coast of Korea. Sedimentary Geology 48, 295-320. 
Choi, S.J., 1987. Study on the Lower Cretaceous charophytes from the Upper Gyeongsang Supergroup. Journal of the Paleontological Society of Korea 3, 79-92.

Choi, S.J., 1989a. Fossil charophytes from the Nagdong Formation in Seonsangun, Gyeongsangbukdo, Korea. Journal of the Paleontological Society of Korea 5 28-38.

Choi, S.J., 1990. Some nonmarine fossils from the central part of Gyeongsang Basin, S. Korea. Journal of the Paleontological Society of Korea 6, 165-179.

Chun, S.S., Chough, S.K., 1992. Tectonic history of Cretaceous sedimentary basins in the southwestern Korea Peninsula and Yellow Sea. In: Chough, S.K. (Ed.) Sedimentary Basins in the Korean Peninsula and Adjacent Seas. Korean Sediment Research Group, Special Publication. Hanlimwon, Seoul, pp. 60-76.

Currie, P.J., Sarjeant, W.A.S., 1979. Lower Cretaceous dinosaur footprints form the Peace River Canyon, British Columbia, Canada. Plaeogeography, Palaeoclimatology, Palaeoecology 28, 103-115.

Dodson, P., 1976. Quantitative aspects of relative growth and sexual dimorphism in Protoceratops. Journal of Paleontology 50, 929-940.

Doh, S.J., Kim, K.H., 1994. A paleomagnetic study of Cretaceous rocks from the Euiseong area. Economic Environmental Geology 27, 263-279.

Ferrusquia-Villafranca, I., Applegate, S.P., Espinisa-Arrubarrena, L., 1978. Rocas volcanosedimentarias Mesozoicas y huellas de dinosaurios en la región suroccidental Pacifica de México. Revista, Instituto de Geologia, Universidad Nacional Autonoma de México 2, 150-162.

Gilmore, C.W., 1933. On the dinosaurian fauna of the Iren Dabasu Formation. Bulletin of the American Museum of Natural History 67, 23-78.

Huh, M., Lim, S.-K., Yang, S.-Y., Hwang, K.G., 1997. A preliminary report on the Cretaceous dinosaur tracks from the Uhangri Formation, Haenam, Korea. Journal of the Paleontological Society of Korea, Special Publication 2, 1-16.

Huh, M., Paik, I.S., Chung, C.H., Park, J.B., Kim, B.S., 2001. Dinosaur tracks from islands in Yeosu, Jeollanamdo, Korea. Journal of the Geological Society of Kore 37, 653-658.

Huh, M., Hwang, K.G., Paik, S.I., Chung, C.H., Kim, B.S., 2003. Dinosaur tracks from the Cretaceous of South Korea: distribution, occurrences and paleobiological significance. Island Arc 12, 132-144.

Huh, M., Paik, I.S., Lockley, M.G., Hwang, K.G., Kwak, S.K., 2006. Well preserved theropod tracks from the Upper Cretaceous of Hwasun County, southwestern South Korea, and their paleobiological implications. Cretaceous Research 27 $123-138$

Hwang, K.G., Huh, M., Lockley, M.G., Unwin, D.M., Wright, J.L., 2002. New pterosaur tracks (Pteraichnidae) from the Late Cretaceous Uhangri Formation, S.W. Korea. Geological Magazine 139, 421-435.

Irby, G.V., 1995. Posterolateral markings on dinosaur tracks, Cameron dinosaur tracksite, Lower Jurassic Moenave Formation, northeastern Arizona. Journal of Paleontology 69, 779-784.

Kim, H.M., 1994. Paleocurrent analysis and depositional history of the Cretaceous Jinju Formation in Jinju-Sachon area, Korea. Journal of the Geological Society of Korea 30, 506-519.

Lee, Y.N., Yang, S.-Y., Seo, S.J., Baek, K.S., Lee, D.J., Park, E.J., Han, S.W., 2000. Distribution and paleobiological significance of dinosaur tracks in the Jindong Formation (Albian) in Kosong County, Korea. Journal of the Paleontolological Society of Korea, Special Publication 4, 1-12

Lee, Y.N., Yu, K.M., Wood, C.B., 2001. A review of vertebrate faunas from the Gyeongsang Supergroup (Cretaceous) in South Korea. Palaeogeography, Palaeoclimatology, Palaeoecology 165, 357-373.

Lee, Y.S., Nishimura, S., Min, K.D., 1999. The Phanerozoic apparent polar wande path for the Korean Peninsula and its tectonic implication. In: Metcalfe, I. (Ed.), Gondwana Dispersion and Asian Accretion, IGCP 321 Final Results Volume. A.A. Balkema, Rotterdam, pp. 197-209.

Lim, S.-K., 1990. Trace Fossils of the Cretaceous Jindong Formation, Koseoung, Korea. Unpulished Ph.D thesis, Kyungpook National University, Daegu, Korea, 128 pp.

Lim, S.-K., 1995. Cretaceous dinosaur tracks in the upper Kyungsang Group. Proceedings of the Annual Meeting of the Geological Society of Korea 1, 10 (abstracts).

Lim, S.-K., Yang, S.-Y., Lockley, M.G., 1989. Large dinosaur footprint assemblage from the Cretaceous Jindong Formation of southern Korea. In: Gillette, D.D. Lockley, M.G. (Eds.), Dinosaur Tracks and Traces. Cambridge University Press, Cambridge, pp. 333-336.

Lim, S.-K., Lockley, M.G., Yang, S.-Y., Fleming, R.F., Houck, K.A., 1994. Preliminary report on sauropod tracksites from the Cretaceous of Korea. Gaia: Revista de Geociencias, Museu Nacional de Historia Natural, Lisbon, Portugal 10, 109-117.

Lim, S.-K., Lockley, M.G., Yang, S.-Y., 1995a. Dinosaur trackways from Haman Formation, Cretaceous, South Korea: evidence and implications. Proceedings of 15th International Symposium of Kyungpook National University, 329-336.

Lim, S.-K., Lockley, M.G., Yang, S.-Y., 1995b. Dinosaur trackways from Haman Formation, Cretaceous, South Korea: evidence and implications. In: Sun, A. Wang, Y. (Eds.), 6th Symposium on Mesozoic Terrestrial Ecosystems and Biota. China Ocean Press, Beijing, pp. 161-164.

Lockley, M.G., 1987. Dinosaur footprints from the Dakota Group of eastern Colorado. Mountain Geologist 24, 107-122.

Lockley, M.G., 1989. Tracks and traces: new perspectives on dinosaurian behavior ecology and biogeography. In: Padian, K., Chure, D.J. (Eds.), The Age of Dinosaurs, Short Courses in Paleontology, 2. The Paleontological Society, PA, pp. 134-145.

Lockley, M.G., 2007. The morphodynamics of dinosaurs, other archosaurs and their trackways: holistic insights into relationships between feet, limbs and the whole body. In: Bromley, R., Melchor, R. (Eds.), Ichnology at the crossroads: a multidimensional approach to the science of organism - substrate interactions. Society of Economic Paleontologists and Mineralogists Special Publication, 88, pp. 27-51.

Lockley, M.G., 2008. Variation in mesaxonic bird and dinosaur footprints: clues to widespread convergence in developmental dynamics. In: Uchman, A. (Ed.), The 2nd International Congress on Ichnology, Cracow Poland, Aug 29-Sept. 82008. Polish Geological Institute, p. 70.

Lockley, M.G., Hunt, A.P., 1995. Dinosaur Tracks and Other Fossil Footprints of the Western United States. Columbia University Press, New York, 338 pp.

Lockley, M.G., Matsukawa, M., 1998. Lower Cretaceous vertebrate tracksites of East Asia. In: Lucas, S.G., Kirkland, J.I., Estep, J.W. (Eds.), Lower and Middle Cretaceous Terrestrial Ecosystems. New Mexico Museum of Natural History and Science Bulletin, 14, pp. 135-142.

Lockley, M.G., Wright, J.L., 2001. The trackways of large quadrupedal ornithopods from the Cretaceous: a review. In: Carpenter, K., Tanke, D. (Eds.), Mesozoic Vertebrate Life. New research inspired by the Paleontology of Philip J. Currie. Indiana University Press, pp. 428-442.

Lockley, M.G., Fleming, R.F., Yang, S.-Y., Lim, S.-K., 1991. The distribution of dinosaur and bird tracks in the Jindong Formation of South Korea: implications fo paleoecology. International Symposium on Origin, Sedimentology, and Tectonics of late Mesozoic to early Cenozoic Sedimentary Basins at the Eastern Margin of the Asian Continent. Kyushu University, Fukuoka, Japan, pp. 61.

Lockley, M.G., Fleming, R.F., Yang, S.-Y., Lim, S.-K., Houck, K., 1992. Dinosaur tracks in intrusive igneous rocks. Ichnos 2, 213-216.

Lockley, M.G., Meyer, C.A., Hunt, A.P., Lucas, S.G., 1994. The distribution of sauropod tracks and trackmakers. Gaia: Revista de Geociencias, Museu Nacinal de Historia Natural, Lisbon, Portugal 10, 233-248.

Lockley, M.G., Huh, M., Lim, S.-K., Yang, S.-Y., Chun, S.S., Unwin, D., 1997. First report of pterosaur tracks from Asia, Chollanam Province, Korea. Journal of the Paleontological Society of Korea, Special Publication 2, 17-32.

Lockley, M.G., Nadon, G., Currie, P.J., 2004. A diverse dinosaur-bird footprint assemblage from the Lance Formation, Upper Cretaceous, Eastern Wyoming: implications for ichnotaxonomy. Ichnos 11, 229-249.

Lockley, M.G., Houck, K., Yang, S.-Y., Matsukawa, M., Lim, S.-K., 2006. Dinosaurdominated footprint assemblages from the Cretaceous Jindong Formation, Hallyo Haesang National Park area, Goseong County, South Korea: evidence and implications. Cretaceous Research 27, 70-101.

Lockley, M.G., Kim, S.H., Kim, J.Y., Kim, K.S., Matsukawa, M., Li, R., Li, J., Yang, S.-Y., 2008. Minisauripus - the track of a diminutive dinosaur from the Cretaceous of China and Korea: implications for stratigraphic correlation and theropod foot morphodynamics. Cretaceous Research 29, 115-130.

Lockley, M.G., Huh, M., Kim, B.S., First report and interpretation of blunt-toed ornithopod tracks and pes-only sauropod trackways from the Hwasun tracksite (Cretacous) Korea. Cretaceous Research (in review).

Matsukawa, M. Lockley, M.G. 2007. Speculations on Cretaceous ornithopod trackway distribution in East Asia: comparison with extant ungulate migration. patternsProceedings of 2007 Haenam Uhangri International Dinosaur Symposium. Chunnam National University Press, Gwangju, pp. 180-206.

Matsukawa, M., Futakami, M., Lockley, M.G., Peiji, C., Jinhua, C., Zhenyao, C., Bolotsky, U.L., 1995. Dinosaur footprints from the Lower Cretaceous of easter Manchuria, northeastern China: implication for the recognition of an ornithopod ichnofacies in East Asia. Palaios 10, 3-15.

Matsukawa, M., Ito, M., Hayashi, K., Takahashi, O., Yang, S.-Y., Lim, S.-K., 1998 Evaluation of nonmarine bivalves as chronological indices, based on examples from the Lower Cretaceous of East Asia. In: Lucas, S.G. Kirkland, J. Estep, JW. (Eds.), Lower and Middle Cretaceous Terrestrial Ecosystems. New Mexico Museum of Natural History Society Bulletin, 14, pp. 125-133.

Matsukawa, M., Lockley, M.G., Hunt, A.P., 1999. Three age groups of ornithopods inferred from footprints in the mid-Cretaceous Dakota Group, eastern Colarado, North America. Palaeogeography, Palaeoclimatology, Palaeoecology 147, 39-51.

Matsukawa, M., Shibata, K., Kukihara, R., Koarai, K., Lockley, M.G., 2005. Review of Japanese dinosaur track localities: implications for ichnotaxonomy, paleogeography and stratigraphic correlation. Ichnos 12, 201-222.

Moratalla, J.J., 1993. Restos indirectos de dinosaurios del reigistro esopanol: paleoeichnologia de la Cuenca de cameros (Jurassic Superior-Cretaceico Inferior) y Paleoologia del Cretacico superior. Unpublished Ph.D Thesis. Universidad Autonoma de Madrid, Departamento de Biologia, Spain, 727 pp.

Moratalla, J.J. Sanz, J.L. Jimenez, S., 1994. Dinosaur tracks from the Lower Cretaceous of Regumiel de la Sierra (province of Burgos, Spain): inferences on a new quadrupedal ornithopod trackway. Ichnos 3, 89-97.

Norman, D.B., 1980. On the ornithischian dinosaur Iguanodon bernissartensis of Bernissart (Belgium). Memoires de I'lnstitut Royal des Sciences Naturelles de Belgique 178, 1-105.

Paik, I.S., Lee, Y.I., 1994. Paleoclimatic records in floodplain lake deposits of the Cretaceous Hasandong Formation in Jinju area, Korea. Journal of the Geological Society of Korea 30, 410-424.

Paik, I.S., Kim, J.Y., 1995. Calcareous paleosols from the Upper Hasandong Formation in the vicinity of Jinju, Korea: implications in floodplain sedimentation and paleoclimate. Journal of the Geological Society of Korea 31, 482-498.

Paik, I.S., Lee, Y.I., 1998. Desiccation cracks in vertic paleosols of the Cretaceous Hasandong Formation, Korea: genesis and paleoenvironmental implications. Sedimentary Geology 119, 161-179.

Paik, I.S., Kim, J.H., Lee, Y.I., 2001. Dinosaur track-bearing deposits from the Cretaceous Jindong Formation, Korea: occurrence, paleoenvironments and preservation. Cretaceous Research 22, 79-92. 
Parkes, A.S., 1993. Dinosaur footprints in the Wealden at Fairlight, East Sussex. Proceedings of the Geologists' Association 104, 15-21.

Paul, G.S., 2006. Turning the old into the new: a separate genus for the gracile iguanodont from the Wealden of England. In: Carpenter, K. (Ed.), Horns and Beaks: Ceratopsian and Ornithopod Dinosaurs. Indiana University Press, Bloomington, pp. 69-77.

Sarjeant, W.A.S., Delair, J.B., Lockley, M.G., 1998. The footprints of Iguanodon: a history and taxonomic study. Ichnos 6, 183-202.

Tateiwa, I., 1925. Geological age of the Nagdong flora. Journal of the Geological Society of Tokyo 32, 493-512.

Tateiwa, I., 1929. Geological Atlas of Korea, no. 10, Kyongju, Yongchon, Taegu, and Waegwan sheets. Geological Survey of Chosen, Korea, 12.

Thulborn, R.A., 1990. Dinosaur Tracks. Chapman and Hall, London, 410 pp.

Tresise, G., 1996. Sex in the footprint bed. Geology Today, 22-26. January-February.

Van Beneden, P.J., 1878. Sur la decouverte de reptiles fossiles gigantesques dans le charbonnage de Bernissart, près de Pruwelz. Bulletin de I'lnstitut Royal d'Histoire Naturelle de Belgique 3 (1), 1-19.

Weems, R.E., 1992. A reevaluation of the taxonomy of Newark Supergroup saurischian dinosaur tracks, using extensive statistical data from a recently exposed tracksite near Culpeper Virginia. In: Sweet, P.C. (Ed.), Proceedings of the 26th Forum on the Geology of Industrial Minerals. Commonwealth of Virginia Department of Mines, Minerals and Energy, Charlottesville, pp. 113-127.

Yang, S.-Y., 1974. Note on the genus Trigonioides (Bivalvia). Transactions and Proceedings of the Palaeontological Society of Japan 95, 395-408.

Yang, S.-Y., 1975. On a new non-marine pelecypod genus from the Upper Mesozic Gyeongang Group of Korea. Transactions and Proceedings of the Palaeontological Society of Japan 100, 177-184.
Yang, S.-Y., 1976. On fossils from the Gyeongsang Group-especially on some of the molluscan fauna. Journal of the Geological Society of Korea 12, 23-30.

Yang, S.-Y., 1978a. Ontogenetic variation of Trigonioides (s.s.) paucisulactus (Cretaceous non-marine Bivalvia). Transactions and Proceedings of the Palaeontological Society of Japan 111, 333-347.

Yang, S.-Y., 1978b. On the discovery of Nippononaia ryosekiana from the Gyeongsnag Group, Korea. Journal of the Geological Society of Korea 14, 33-43.

Yang, S.-Y., 1979. Some new bivalve species from the Lower Gyeongsnag Group. Transactions and Proceedings of the Palaeontological Society of Japan 116, 223-234.

Yang, S.-Y., 1982a. On the dinosaur's footprints from the Upper Cretaceous Gyeongsang Group, Korea. Journal of the Geological Society of Korea 18, 138-142.

Yang, S.-Y., 1982b. Geology around the type-locality of Trigonioides (s.s.) kodairai and age of the Nagdong Subgroup. Journal of the Geological Society of Korea 18, 67-72.

Yi, M.S., Cho, B.H., Chi, J.M., 1994. Palynomorphs from the Jinju Formation in the Euiseong area, Korea. Journal of the Paleontological Society of Korea $10,41-56$.

You, H., Azuma, Y., 1995. Early Cretaceous Dinosaur Footprints from Luanping, Hebei Province, China. Sixth Symposium on Mesozoic Terrestrial Ecosystems and Biotas. China Ocean Press, Beijing, pp. 151-156.

Zhang, J., Li, D., Li, M., Lockley, M.G., Bai, Z., 2006. Diverse dinosaur-, pterosaur- and bird-track assemblages from the Hakou Formation, Lower Cretaceous of Gansu Province, northwest China. Cretaceous Research 27, 44-55.

Zhao, X., Li, D., Han, G., Zhao, H., Liu, F., Li, L., Fang, X., 2007. Zhuchengosaurus maximus from Shandong Province. Acta Geoscientica Sinica 28 (2), 111-122. 